\title{
DEVELOPMENT OF INFORMATIONAL AWARENESS AMONG STUDENTS UNDER THE CONDITIONS OF DIGITAL EDUCATION IMPLEMENTATION IN YAKUTIA
}

\author{
Elizaveta Afanasieva Barakhsanova ${ }^{1}$ \\ Nikolai Petrovich Olesov ${ }^{2}$ \\ Liudmila Vitalievna Popova ${ }^{3}$ \\ Anna Iliinichna Danilova ${ }^{4}$ \\ Nikolai Semyonovich Diachkovskyi ${ }^{5}$
}

\begin{abstract}
This study was aimed at determining the effectiveness and potential of pedagogical education to develop informational awareness among students under the conditions of educational digitalization in Yakutia, also known as the Republic of Sakha. The problem was investigated primarily through an analysis of the theoretical
\end{abstract} \begin{abstract}
viewpoints put forward by foreign and Russian researchers on issues regarding updates to education in the informational education space. The loss of moral and value orientations in society and the upbringing amid this backdrop of an entire generation of youth, who are currently becoming educators of a new rising generation, cause societal
\end{abstract}

\footnotetext{
${ }^{1}$ Doctor of Pedagogical Sciences, Professor, Head of the Department of Informatics and Computer Engineering, M. K. Ammosov North-Eastern Federal University, 677000, Yakutsk, Russia, email: ebarahsanova@yandex.ru, ORCID: 0000-0003-3327-8773, AuthorID: 268975

${ }^{2}$ Candidate of Pedagogical Sciences, Associate Professor of the Department of Theory and Methods of Physical Culture and Life Safety, Institute of Physical Culture and Sports, M. K. Ammosov North-Eastern Federal University, 677000, Yakutsk, Russia, ORCID: 0000-0002-8396-9559, AuthorID: 794113

${ }^{3}$ Candidate of Pedagogical Sciences, Associate Professor of the Department of Preschool Education, M. K. Ammosov North-Eastern Federal University, 677000, Yakutsk, Russia, ORCID - 0000- 0003-1990-7158, ID - 443328

${ }^{4}$ Candidate of Pedagogical Sciences, Associate Professor, Head of the Department of Psychology and Pedagogy, FSBEI of Higher Education "Churapchinsky State Institute ofPhysical Culture and Sports," Churapcha community, ORCID: 0000-0003-2054-2555, AuthorID: 308266

${ }^{5}$ Candidate of Medical Sciences, Associate Professor, Head of the Department of Nursing, M. K. Ammosov North-Eastern Federal University, 677000, Yakutsk, Russia, ORCID: 0000-0002-8317-8538, SPIN-code: 7721-0898, AuthorID: 316557
} 
apprehension and highlight the need to find a solution. Correspondingly, this research probed into the effectiveness with which the following requirement is implemented in the chosen context: capitalizing on the potential of ethnic pedagogy in advancing the evolution of students' ability to discern and adequately assess the effects of informational environments on youth development. A pedagogical experiment was conducted at the M. K. Ammosov North-Eastern Federal University to examine initial concepts regarding the fulfillment of ethnic pedagogy's prospects for enhancing the educational value of academic activities in the university. More than 500 students from different colleges and faculties, as well as lecturers who are involved in extracurricular activities, took part in the experiment. The study treated updates in service of the potential of ethnic pedagogy to mold the young generation under the digitalization of the educational process in a regional university as scientific results. The practical significance of the study was established in consideration of the characteristics of media influence, Internet addiction, and psychophysiological stress and in accordance with the requirements of the newly instituted Federal State Educational Standard 3++ (FSES 3++). The obtained methodological and technological data on the development of informational awareness among students can be used in explorations into other areas of education.

Keywords: education, development, informational awareness, visualization, educational potential, educational information environment.

\section{Introduction.}

The need to update the principles of character education at the present era was induced by the cardinal changes in people and social communities that have occurred over the last relatively short period of time. These changes manifest themselves as alterations to society's system of values, which in turn, drive changes in methods of exerting educational influence and prevent the use of the educational frameworks of older generations in the upbringing of younger generations. The search and implementation of promising approaches to education are also 
stimulated by the fact that modern society has become informational and virtual in nature, with the youth being more frequently preoccupied with the digital world than with real life (Ali, Alaa, and Wid, 2018).

Today, we can see the emergence of novel phenomena that were not known in the past. The social, cultural, and everyday environments that significantly affect the lifestyles and worldviews of modern individuals have also changed. As a consequence of these developments, existing traditional educational systems have become a serious obstacle to cultural and social transformations in Russian society, where new promising approaches to educating young people are needed (Vinokurova, 2017; Petrova, 2000; Volchik, Maslyukova, 2019).

The problematic field of conceptual approaches to education through modern pedagogy, particularly ethnic pedagogy, is extensive. All these approaches reflect a critical position in relation to traditional education, which, according to researchers, does not correspond to changed social conditions and new educational situations. Insufficient consideration of the ideas that underlie the environmental approach is detrimental to pedagogical practice and its results - an assertion that has been repeatedly confirmed in recent decades throughout the entire Russian system of education. Education as a concrete historical phenomenon is closely related to the socioeconomic, political, and cultural conditions of society, as well as its ethnoconfessional and sociocultural features (Berezhnova, Nabok, and Scheglov, 2013).

In a broad social sense, upbringing is the function of society to prepare younger generations for life. This function is carried out by an entire social structure, which encompasses public institutions, organizations, the church, the media and culture, and families and schools (Gafurova, 2009). Therefore, comprehensively speaking, the "education of a modern person" in the framework of our study is understood as a familiarization of an individual with the modern information society; it involves the formation of the ability to recognize information problems and find solutions to these issues.

The Federal State Educational Standard of the third generation (FSES $3++)$ provides guidelines on the 
development of universal educational actions, namely, the personal, regulatory, cognitive, and 2. Literature review.

communicative. The main indicators of The current time period, which the achievement of personal results include the one's views; explain the meaning of one's assessments, motives, and goals to determine values in life; critically evaluate and adjust one's behavior; and independently detect and form social problems. In this regard, in a regional system of education under conditions of digitalization, one of the main pedagogical tasks of educational informatization is to take advantage of the educational potential of ethnic pedagogy.

Modern society lives in an era of information wars, where the informatization of education should act as an information and social filter. One of the essential activities of digital education is to educate a person who wants to know the truth in the face of multivariate information to enable him/her to make an informed decision on the basis of a thoughtful critical attitude toward any message, different sources of information, and their analysis (Radif, Mohammed, 2019). is reflected in upbringing, features a change in the educational paradigm that offers a different content of education, different approaches to its subjects, a different right of the subjects, other relations between the subjects, a different position in the teacher-student activities. The origins of this educational paradigm lie in the innovative processes of upbringing and are based on the experience of "new schools" of the late 19th and early 20th centuries: the schools of "free education" (Lev Tolstoy in Yasnaya Polyana), "labor schools" (the Gorky colony and the commune of Dzerzhinsky directed by Anton Makarenko), "The Invigorating Life" (Shatsky), "House of a Free Child" (Montessori) and others (Piskunova, 2001).

The idea of environmental education in international pedagogy was realized in the experience of German socalled neighboring integrated schools (Nigermeier, Zimmer), French “parallel school" (Porsche, Ferra), American "schools without walls" (Walter, Watson, Hosken), schools of the "eco- 
system" (Goodland) (Piskunov, 2001).

In this paper, we strive to draw attention to the promotion of the potential of ethnic pedagogy in the process of education, which is increasingly mentioned by modern researchers in various fields of science. The use of the folk principles of education as a tendency in the development of modern mankind was especially pronounced in the second half of the 20th and in the beginning of the 21 st centuries. At that time the formation of ethnic pedagogy was promoted by a lot of research papers. In particular, the indigenous scientist $\mathrm{V}$. Afanasyev (Aldanskyi) from Yakutia published the book Ethno-Pedagogy of the Non-Russian People of Siberia and the Far East in 1979. The book deals with the educative role of ethnic pedagogy in the process of education, the moral, aesthetic, mental and physical foundations of the traditional education (Afanasyev, 1979).

For the first time the ethnic pedagogy as an independent field of scientific knowledge was considered in the monograph by G. Volkov, which was published in 1974. In his book EthnoPedagogy academician G. Volkov gives the following definition: "Ethno- pedagogy is a science of the empirical experience of ethnic groups in raising and educating children, of moral, ethical and aesthetic views on the traditional values of the family, clan, tribe, people, nation" (Volkov, 2002).

The problem of translation of the traditional ethnic culture becomes even more complicated with the intensification of the world processes (Panfilova, 2017; Lipets, 2014). Preservation of the cultural heritage, increasing the degree of its influence on the formation of the cultural foundation of modernity is the most important problem of education in modern conditions. The process of forming a modern mass-society, the process of modernization, does not contribute to the real preservation of the traditional cultural ethnic heritage; on the contrary, it may well cause humanity to lose its ethnic culture altogether $\mathrm{Xu}$, Hamamura, 2014; Zeng, Greenfield, 2015).

The human society at the present stage indeed is undergoing a protracted transition from the traditional type of society to the modern. This transition (modernization) is of dramatic nature-it entails personal and social 
changes (Zambakari, 2018; Sun, Ryder, 2016). Traditional foundations are crumbling and the loss of traditions does not always lead to acquiring an innovative nature (Linetskyi, 2017; Gorokhov, 2015; Alampiev, 2018). There comes a general, "global," universal order.

Digital inequality, the closed nature of society, primarily in a situation of scientific, and educational isolation, pose an urgent task that requires updating of the ethnocultural and ethnosocial functions of educational organizations to solve educational issues. Ethnic pedagogy, as a science that transitions to digital education, has various axiological directions.

The analysis of ethnopedagogical theories and practices in the Russian educational system allows us to identify seven areas of ethnic pedagogy as a science: environmental, ethnocultural, sociocultural, physical, labor, creative, and spiritual education. Ethno-pedagogical practice as a science, as an educational discipline, and a technology of upbringing in accordance with its legitimization in the field of education, reveals immense creative potential in all areas of upbringing and creativity of life (Vinokurova, 2017).

The study is interested in the ideas that consider the ethnic aspects of the modern cultural process and are widely covered in the scientific literature. Particularly, the works that are dedicated to the study of the features of ethnic cultures and their interaction with each other (Kane, Jacobs, 2015). The authors of these works understand ethnic culture primarily as an ethnocultural identity, a basic anthropological need (Gerasimova, Gusenkova, 2017), a community of spiritual life, and a national self-awareness (Zykin, Tufanov, 2015). It is the totality of material and spiritual values created by ethnos and passed from generation to generation (Kshnyakin, 2016), that are inevitably transformed in the modern society (Ryazanov, 2017).

In modern conditions, updating the educational potential of ethnic pedagogy is successfully used as an invariant methodology by the national gymnasiums of Tatarstan, Bashkortostan, Chuvashia, and Sakha (Yakutia) (Vinokurova, Petrova, 2000; Baisheva, Semenova, Vinokurova, 2015). In the ethnolinguistic and cultural 
models of national gymnasium education, the educational process is aimed at developing a person of national and Russian culture, who at the same time is a citizen of the world. Ethnodidactic teaching and upbringing methods are used to teach individual subjects as a technology of practiceoriented learning (Baisheva, Andreeva, Dedukina, Maksimova, Nikolaeva, Makarova, 2017).

The issues surrounding the development of a holistic spiritual and moral worldview and the recognition of the unity of cultures and nations are being updated. But the problem lies in the fact that, very often, the ideal of human behavior, an example of morality and integrity presented by the modern mass culture, including Western culture, is very different from an ideal based on the origins of the culture of our people. At the present stage of development in ethno-pedagogy, its field of study and basic concepts, such as "folk culture," "traditional folk education," "folk pedagogy," and "ethnic education," are defined. In his book Ethno-Pedagogy, Volkov (2002) warns that a negative example can have dire consequences, especially if it is shown to a child who has not yet matured.

Indeed, the real spiritual life of Yakutia goes along an eclectic path and can be specifically described as "not quite traditional, but also not quite Western," "semi-traditional and semiWestern," "both traditional and Western at the same time," and so on. This proves the fact that the presence of a national tradition in society is actually inevitable, especially in the upbringing of the younger generation based on ethnic pedagogy (Barakhsanov, Barakhsanova, Golokova, Kronnikov, 2017). In the process of modernization, tradition and modernity become more and more intertwined with each other and form something unified.

The essence of modernization lies in its compliance with the development trends of the modern world, but the successful movement of modernization lies not only in overcoming obsolete traditions, but also in the constructive use of traditional forms as additional incentives for renewal.

\section{Materials and methods}


The methodical review of the views of various researchers on the process of updating ethnic pedagogy in the informational education space was completed as part of this study. Such a methodological procedure is important because of the significance of folk pedagogy and the need to study ethnic. Studies on ethnic pedagogy contribute to some of the most important tasks of raising children: to teach the younger generation how to interact with society, to help them grow into spiritually and morally mature people who know and respect their historical roots.

Today, the aim of education is to raise a well-rounded and moral human being with a base of cultural values and appreciation for the uniqueness of the spiritual life of his/her people. Children develop respect for their own culture and the culture of other nations as well as a pro-active attitude through learning the cultural heritage of their people, the distinctiveness of their traditions.

The great importance of ethnic pedagogy in the system of Russian education in the context of FSES 3++ is expressed in "ensuring, maintaining, and developing the cultural diversity and linguistic heritage of the multinational people of the Russian Federation, mastering the spiritual values and culture of the multinational people of Russia ..." (FSES, 2018).

So, in connection with the personal qualities that should develop as a result of mastering the main educational program, the following requirements are presented:

1. Development of national self-awareness, the formation of values of the multinational Russian culture and humanistic value system (Baisheva et al., 2017);

2. In the new digital economy, a new model of pedagogical education should be built using traditional methods along with innovative, educational technologies and tools (Barakhsanova et al., 2017).

The study identified a number of important factors regarding the significance of informational on the retention and acceptance of information, understanding information's place in the educational process. The study clarifies how the information and social component "work" as a pedagogical phenomenon in the ethno-pedagogical context of digital education implementation in the region. In our 
opinion, the development of informational awareness can be the goal of the educational process, contributing to the successful retention of educational and behavioral content.

In total, more than 450 students participated in the study. Bachelor's degree holders as well as candidates for Master's degrees at the North-Eastern Federal University n.a. Ammosov took part in the student survey.

\section{Results}

An analysis of the psychological and pedagogical literature allowed us to conclude the following: under the conditions of informatization and globalization of education, personal awareness manifests itself in the ability to determine the emotions and thoughts of a person, which allows to determine a person's mood, to be at ease during a conversation, to understand and accept the talker, and also in the ability to evaluate yourself and your actions from the side.

$$
\text { Informational }
$$

awareness provides an understanding of how do you feel about the information technologies and how another person feels about them.

Informational awareness is an active, spiritual, mental and physical work, aimed at understanding the dependence of society and education on the information, the social problems of the information society, assessing and determining the significance of the ability to see positive and negative aspects of the influence that modern information technologies have in different life situations.

The signs of informational awareness and their manifestations underlie the definition of criteria and indicators of informational awareness (Table 1).

Table 1 - Criteria and indicators of informational awareness

\begin{tabular}{|c|c|}
\hline Criteria & Indicators \\
\hline $\begin{array}{l}\text { The ability to see and } \\
\text { assess informational phenomena }\end{array}$ & $\begin{array}{l}\text { - Ability to pay attention and take interest } \\
\text { in the information society, nature, world; } \\
\text { - Ability to take interest in socially } \\
\text { important informational problems; }\end{array}$ \\
\hline
\end{tabular}


Periódico do Núcleo de Estudos e Pesquisas sobre Gênero e Direito

Centro de Ciências Jurídicas - Universidade Federal da Paraíba

V. 9 - $\mathrm{N}^{\circ} 02$ - Ano 2020

ISSN | 2179-7137 | http://periodicos.ufpb.br/ojs2/index.php/ged/index

349

\begin{tabular}{|c|c|}
\hline & $\begin{array}{l}\text { - Ability to analyze informational } \\
\text { problems. }\end{array}$ \\
\hline $\begin{array}{l}\text { The ability to view } \\
\text { information critically }\end{array}$ & $\begin{array}{l}\text { - Ability to compare and evaluate } \\
\text { different sources of information and points of } \\
\text { view; } \\
\text { - Ability to argue your point with } \\
\text { references to reliable facts; } \\
\text { - Ability to filter the incoming } \\
\text { information on the base of your knowledge, value } \\
\text { system and life experience. }\end{array}$ \\
\hline $\begin{array}{l}\text { The ability to determine } \\
\text { your place in the information } \\
\text { society }\end{array}$ & $\begin{array}{l}\text { - Ability to be at ease during a } \\
\text { conversation, to pay attention to the talker; } \\
\text { - Ability to show initiative and } \\
\text { independency in organization and realization of } \\
\text { informational activity; } \\
\text { - Ability to show mobility in the face of } \\
\text { new terms and connection relations through } \\
\text { networking technology. }\end{array}$ \\
\hline
\end{tabular}

The identified criteria and on the frequency of displayed indicators indicators made it possible to determine and the meaningful presentation of its the relative levels of development of the signs: situational and stable-active.

students' informational awareness based

Table 2 - The levels of informational awareness development

\begin{tabular}{|c|c|}
\hline Level & Expression \\
\hline Situational & - Lack of desire to participate in community affairs; \\
& - Lack of interest and attention to other people; \\
& - Expression of interest in informational phenomena \\
& only in certain situations.
\end{tabular}




\begin{tabular}{|l|l|}
\hline \multicolumn{1}{|c|}{ Stable- } & - Expression of rationality, valuation activity; \\
active & $\begin{array}{l}\text { - Positive attitude towards and interest in the processes } \\
\text { of information; } \\
\end{array}$ \\
\hline
\end{tabular}

In the course of studying informational awareness among students, we determined that it manifests itself in the ability to find and see social problems, to evaluate them, determine their significance for the society and for oneself, to see connections, relationships, to assess and make decisions and in the ability to easily find your bearings in different life situations.

To determine the level of development of informational awareness in relation to socially significant problems by means of ethnic pedagogy, we conducted a survey of 450 students studying at the Ammosov North-Eastern Federal University.

At the first stage of the study we conducted a survey to determine the level of professional and informational competence of students who are getting their Master's degree. The results show that $65 \%$ of students in their first and second years of study do not have work experience, which indicates that most students have no idea about the special aspects of their future professional activities. $20 \%$ of the students have work experience up to 1 year and the smallest percentage of respondents have work experience from one to five years $(15 \%$ of students).

The survey included questions about the improvement of their informational and professional competence. $82 \%$ of students think that the most important things are the ability to plan and organize their activities and the ability to make decisions. $53 \%$ of the Master's candidates think that effective work requires leadership skills and $18 \%$ of students find necessary the skills of delegation. In our opinion, this is due to the lack of managerial practice, where the distribution of functions, delegation skills, the ability to determine one's own leadership potential are necessary.

Communicative and personal competences were determined at the second stage of the study. While assessing communicative competencies, students pointed out persuasion skills 
(87\%), contact skills (74\%), flexibility (71\%). Only $51 \%$ of respondents think that teamwork and listening skills are necessary competencies of a successful manager in education. We believe that this is due to the lack of work experience in real teams and the insufficient development of communicative skills.

When assessing personal competencies, Master's students marked responsibility $(93 \%)$, desire for selfimprovement (68\%), and resistance to stress (52\%) as highly necessary competencies of managers in education. Only $35 \%$ of respondents considered creativity as an obligatory competency of an educator. Among the special competencies, students marked only the ability to apply knowledge in practice as a necessary competence of an educator (59\%). Students found all other competences as optional. Perhaps this is due to lack of knowledge of the specific place of future employment and lack of practical experience.

When describing their strengths, Master's candidates pointed out sociability, creative approach to problem solving, high professional motivation, and the ability to plan and control their work, while the lack of practical work experience and inability to apply theory in practice were considered as weaknesses.

The students made the following proposals for improvement of professional competences and change in the educational process: increase the number of hours for internship, organize internships with the option of subsequent employment, increase the amount of practicum classes, reduce the amount of lecture classes, organize practicum classes with the aim to develop specific skills and competences. There were also suggestions to organize meetings with successful managers of educational institutions for experience exchange on a regular basis.

The third stage of the survey was meant to determine the level of informational awareness development of the students. The study was carried out using the questionnaire developed by the authors on the basis of the methodology developed by M. Rozhkov in The Study of the Socialized Personality of Students. The level of development of the ability to see and assess informational phenomena was determined using the test developed by N. Schurkova in Reflection on Life Experience and 
through pedagogical observation. The level of development of the ability to view the information critically was determined using the questionnaire on knowledge of the facts of social reality, the methodology in Analysis of Communicative Situation and methods of text content analysis. The level of development of the ability to identify your place in the information society was determined by using the methodology of evaluating the level of students' education by G. Faizulina, the methodology of interpersonal relationship diagnostics by T. Lire, and through pedagogical observation and quality analysis.

The results of the educational experiment helped to draw attention to the following facts:

- The students are informationally aware of the social problems of the modern society; they are able to establish the reasons for such problems and suggest methods of their solution;

- Approximately $45 \%$ of the students take interest in information phenomena only in certain situations, their understanding of spiritual and moral norms is fragmental, their desire to participate in community affairs is lacking;

- The students of today have knowledge of those social groups to which they belong, the knowledge of other social strata is scarce.

Assessment of the reliability of the research results revealed positive trends of the development of informational awareness among students. The idea of educating informational awareness in educational activities is based on a combination of the educational potential of ethnic pedagogy and methodological approaches to the informatization of education.

\section{Discussion}

Today the regional education system has entered a phase of significant transformations caused by the global digitalization of society. To be effective under the circumstances the pedagogical education has to change quickly, and to change at an even faster pace to be advanced. Previous educational models and methods of their implementation are becoming less effective, old methods of communication between participants of the educational process often do not 
work, types of students' activities, models of obtaining and working with knowledge change.

Pedagogical universities have to develop a strategy for improvement under the conditions of dynamic digital modernization of the whole system of education. Due to the fact that the pedagogical education is the one that underlies all innovations, the progressive development of the Northern region of Russia directly depends on the effectiveness of the digitalization of this particular education.

The pedagogical education in Russia traditionally strives for advanced educational technologies and breakthrough educational strategies, but so far this is not being implemented on such a significant scale that we would like to observe. One of the main problems at the moment is the lack of qualified teaching staff that possesses the required competences in the field of digitalization of education with the consideration of ethnic factor.

To overcome this omission, regional pedagogical universities need to reform their training programs and the system of further education for already working teachers, which will be activating the educational potential of ethno-pedagogical tools in studying the influence of modern technologies on the development of the younger generation.

Undoubtedly, if the managers of the universities purposefully and systematically initiate teachers to study the tools of a digital teacher and integrate them into professional activities, strive to develop the innovative culture of the entire teaching team and the need to move forward in a coordinated manner, the universities under the authority of such managers would become leaders in development.

The most significant and interesting result is to change not only the educational technologies, but also the way of thinking and the culture of the teaching staff.

Let's highlight several key areas of updating the education of the younger generation in the context of the implementation of digital education in Yakutia:

1. It is necessary to understand that the student of today is involved in the digital world almost from birth. The study of his/her educational needs is a key aspect in changing pedagogical education in terms of digital education. 
A student today chooses a university, where he/she gets the possibility to get a new knowledge in a timely, convenient, fast and easy manner, where he/she will also be shown how this new knowledge works. Consequently, the university needs all the tools and the ability to adapt to the rapidly changing culture of teaching and learning. A modern student is interested not just in the set of acquired knowledge, but in the process of interacting with the teacher on a dialogue basis, on the basis of development and mobility. A student is interested in the use of digital tools and technologies in education, which are relevant in his/her life.

2. It should be noted that digital education is based on the principle of open education and flexible integration. This allows the educational organization to find new non-standard breakthrough solutions in the development of its educational activities through integration with other educational partner organizations. Digital partnership is becoming an important factor in scaling an organization's reach. It allows educational organizations to conduct the teaching and learning process anywhere in Russia or within another country regardless of geography or attendance.

3. It is necessary to seek and introduce innovations to update education. Because of the digital technologies, modern education is undergoing a transition from a model of preliminary pedagogical planning to a model of constant pedagogical experimentation. In this regard, we believe that it is necessary to organize regional centers of digital educational innovations with regard to updating the educational potential of ethnic pedagogy.

With the help of digital technologies, regional pedagogical universities have a new field for competition outside of the market of their current educational services; they now have the opportunity to expand their audience by educating new students and attendees; they also can provide operational support to students almost around the clock as necessary, using eteaching tools and online-education technologies.

The effectiveness of the education of informational awareness among students can be determined using the developed diagnostic tools, which are 
implemented on the basis of selected criteria (see Table 1). These criteria help to monitor the dynamics of the informational awareness indicators, which in turn allows us to determine the level of development of the informational awareness and to adjust further educational work, accordingly.

The significance of the research results for practice is confirmed by the fact that new directions of students' socialization were developed and introduced in the context of the implementation of digital education at the regional pedagogical university through the education of information awareness in educational activities at the university on the base of the ethnic pedagogy of the Sakha people.

\section{Conclusion}

As a result of the study, it was revealed that updating the educational potential of ethno-pedagogy during the development of informational awareness among students gives reason to state that digital education as one of the most important areas in the education and upbringing system is a meaningful and strategically managed process. This circumstance is especially important to consider for educational organizations that, when implementing digital education, do not pay due attention to updating educational potential and to the development of informational awareness among students.

The introduction of innovative digital culture in the educational process involves the transformation and adaptation of models and teaching technologies to the digital realities of life and learning, the widespread use of public knowledge about the impact of information technology on the upbringing and development of the younger generation, intensive and targeted preparation of the teachers for changes in their work, in their role in the educational process and in the equipment of their workplace.

Among other things the experiment included the analysis of regional practices and helped to identify the advantages that update the educational potential of ethnic pedagogy in the context of the implementation of digital education in Yakutia. The specific example of the development of informational awareness among students shows that the process of training new digital-format specialists requires 
substantial, procedural and instrumental changes in the very processes of upbringing and educating.

The analysis of the literature shows that, despite its wide and diverse coverage, the subject of educating young people under the conditions of the transition to digital education in Yakutia in the context of the ethnic culture of a modernizing society is not sufficiently developed, and that fact had motivated the authors to conduct this study.

\section{Bibliographic References}

Afanasiev, V.F. (1979), Ethno-Pedagogy of Non-Russian People of Siberia and Far East: A Monograph. Yakutsk: Yakutknigizdat

Afanasieva, A.B. (2008), "Improving the Ethno-Cultural Education of Modern Educators", People and Education, 4(17), 34-38.

Alampiev, O.A. (2018), "The Features of Economical Differentiation and Traditional Egalitarianism: Challenges of Modernization for the Belarus Society", Social and Humanitarian Knowledge, 1, 90-100.
Ali, S.H., Alaa, K.H., Wid, A.A. (2018), “Analyzing Students' Answers Using Association Rule Mining Based on Feature Selection", Journal of Southwest Jiaotong University, 53(5). http://jsju.org/index.php/journal/article/ view/236.

Baisheva, M.I. (2008), EthnoPedagogical Views of The People of Sakha: A Monograph. Novosibirsk: Science.

Baisheva, M.I., Andreeva, L.D., Dedukina, M.I., Maximova, L.I., Nikolaeva, A.V., Makarova, T.A. (2017), "Etnocultural Traditions as Sources of Maintenance of Spiritually Valuable Bases of Safety of the Person", Man in India, 97(15), 201-210.

Baisheva, M.I., Grigoryeva, A.A., Neustroeva, A.N., Borisova, T.M., Sidorova, E.E., Iliynova, T.L. (2017), "Spiritual Dominance of The Sakha People Traditional Belief in The Personality Development of Children", Journal of Social Studies Education Research, 8(3), 139-148. 
Barakhasanov, V.P., Barakhasanova,

E.A., Olesov, N.P., Prokopyev, M.S. (2018), “E-Learning System Application for Physical Education and Sports Specialist Training", Theory and Practice of Physical Culture, 7, 4.

Barakhasanova, E.A., Vlasova, E.Z, Golikov, A.I., Kuzin, Z.S., Prokopyev, M.S., Burnachov, A.E. (2018), "Peculiarities of Quality Management of Teachers in E-Learning Training in the Arctic Regions", Education, 38(55), 25. Barakhsanov, V.P., Barakhsanova, E.A., Golokova, V.S., Kronnikov, N.D. (2017), "Ethno-Educational Aspects of Intellectual Games Development Process in Sakha (Yakutia)", Theory and Practice of Physical Culture, 7, 34.

Barakhsanova, E.A., Malgarov, I.I. (2018), "Schoolchildren in a Digital Educational Environment: Conditions, Preferences, Security", Problems of Modern Teacher Education, 61(2), 6466.

Berezhnova, L.N., Nabok, I.L., Scheglov, V.I. (2013), Ethno-Pedagogy: Textbook for Universities. Moscow: Academy.
Ethnic Pedagogy of Love and National Salvation: A Joint Monograph. (2017), Yakutsk: Media-Holding Yakutia.

Federal Law on Education in the Russian Federation. (2016), Moscow: Prospect.

Federal State Educational Standard of Elementary General Educationm at https://fgos.ru/

Gafurova, N.V., Bugaeva, T.P. (2009), "Educational Process in a University as a System", Higher Education in Russia, 6, 102-106.

Gerasimova, I.A., Gusenkova, S.S. (2017), "The Formation of Ethnic Culture of Youth as a Socio-Cultural Problem", Culture and Education, 2(25), 85-92.

Kane, M., Jacobs, R. (2015), "Beliefs About Safety and Religious and Cultural Diversity", Journal of Social Service Research, 41(5), 622-641.

Kshnyakin, E.V. (2016), “Translation of Mordovian Ethnic Culture in Modern Conditions", Modern Research and Development, 7(7), 421-424. 
Mamedov, A.K. (2015), Informational

Context of Social Inequality. Materials of the international conference. Argun Readings. Yakutsk: Publishing House Agiki.

Nikolaeva, A.D., Barakhsanova, E.A., Golikov, A.I. (2014), "Strategic Priorities for Modernizing the System of Continuing Teacher Education”, Modern Issues of Science and Education, 4, 8389.

Petrova, T.N. (1989), Chuvash Pedagogy as a Phenomenon of World Civilization. Moscow.

Piskunov, A.I. (2001), The History of Pedagogy and Education. Moscow: Art Center.

Radif, M., Mohammed, N.A. (2019), “Computer Science Teacher's Perception and Needs towards ELearning in Iraq", Journal of Southwest Jiaotong University, 54(5). http://jsju.org/index.php/journal/article/ view/412.

Ryazanov, A.V. (2017), "Features of Ethnic and National Cultures in the
Modern World: Aspects of Transformation", Current Problems of the Humanities and Socio-Economic Sciences, 11(S5), 94-97.

Semyonova, A.D., Vinokurova, U.A. (2015), Modern Ethno-Pedagogy. Schoolbook. Yakutsk: Publishing House of the North-Eastern Federal University.

Sun, J., Ryder, A. (2016), “The Chinese Experience of Rapid Modernization: Sociocultural Changes, Psychological Consequences?”, Front Psychol, 7, 477.

Vinokurova, U.A. (2016), Indigenous Methology in Social and Humanitarian Sciences. Global Bibliosfera (Ariadne's Thread). Sofia: Publishing House Za bukvite-O Pismeneh.

Vlasova, E.Z., Barakhasanova, E.A., Goncharova, S., Aksyutin, P., Kuzin, Z.S., Prokopyev, M.S. (2018), "Effective Adaptive Training of Students in Russian Pedagogical Universities to Use E-learning Technologies", Education, 39(23), 10.

Vlasova, E.Z., Goncharova, S.V., Barakhsanova, E.A., Karpova, N.A., 
Iljina, T.S. (2019), “Artificial Intelligence for Effective Professional Training of Teachers in the Russian Federation", Espacios, 40(22), 9.

Volchik, V., Maslyukova, E. (2019), "Trust and Development of Education and Science", Entrepreneurship and Sustainability Issues, 6(3), 1244-1255.

Volkov, G.N. (2002), Pedagogy of Love. Selected Ethno-Pedagogical Works in 2 Vol. Moscow: Publishing House Magistr-Press.

Xu, Y., Hamamura, T. (n.d.), "Folk Beliefs of Cultural Changes in China", Front. Psychol, 5.

Zambakari, C. (2018), "Modernization Theory and the Metaphor of the Development Ladder", Harvard Africa Policy Journal, 2, 14-38.

Zeng, R., Greenfield, P. (2015), "Cultural Evolution Over the Last 40 years in China: Using the Google Ngram Viewer to Study Implications of Social and Political Change for Cultural Values", Moscow: Int. J. Psychol, 50, 47-55.
Zhuravleva, S.V. (n.d.), "Historical Review of the Formation of the Concept of "Educational Environment." Scientific Review”, Pedagogical Sciences, 3, 65 .

Zykin, A.V., Tufanov, A.O. (2015), “On the Formation of Concepts of National and Ethnic Culture and the Features of Their Content", News of the St. Petersburg State Agricultural University, 38, 344-349 